\title{
PEMBUATAN BIOETANOL DARI TEPUNG AMPAS TEBU MELALUI PROSES HIDROLISIS TERMAL DAN FERMENTASI SERTA RECYCLE VINASSE (PENGARUH KONSENTRASI TEPUNG AMPAS TEBU, SUHU DAN WAKTU HIDROLISIS)
}

\author{
Bambang Trisakti, Yustina br Silitonga, Irvan \\ Departemen Teknik Kimia, Fakultas Teknik, Universitas Sumatera Utara \\ Jl. Almamater Kampus USU Medan, 20155 Indonesia \\ Email : yustina_silitonga@yahoo.com
}

\begin{abstract}
Abstrak
Penelitian ini bertujuan untuk mengetahui pengaruh konsentrasi tepung ampas tebu, suhu dan waktu hidrolisis terhadap yield glukosa dan perolehan kadar glukosa dari proses recycle vinasse. Bahan utama yang digunakan adalah limbah padat ampas tebu dari toko minuman air tebu. Variabel-variabel yang diamati antara lain konsentrasi tepung ampas tebu dalam air, suhu dan waktu hidrolisis termal. Ampas tebu dihancurkan dengan blender sampai berbentuk powder lalu ditambahkan akuades dengan konsentrasi 2,94; 3,85 dan 4,76\% lalu dihidrolisis dalam tangki hidrolisis. Proses hidrolisis berlangsung pada suhu 135, 150 dan $165^{\circ} \mathrm{C}$ dengan waktu hidrolisis 1 , 1,5 dan 2 jam. Kemudian hasil hidrolisis (hidrolisat) diuji yield glukosa serta kadar lignin dan selulosanya lalu dilanjutkan dengan proses fermentasi untuk menghasilkan bioetanol. Hasil fermentasi kemudian disaring untuk diperoleh vinasse-nya lalu di-recycle menjadi umpan hidrolisis. Hasil penelitian menunjukkan bahwa yield glukosa meningkat seiring dengan meningkatnya konsentrasi tepung ampas tebu, suhu dan waktu hidrolisis. Namun, yield glukosa meningkat pada waktu hidrolisis 1 hingga 1,5 jam kemudian menurun pada waktu hidrolisis 1,5 hingga 2 jam. Perolehan yield glukosa tertinggi diperoleh pada konsentrasi tepung ampas tebu $2,94 \%$, suhu $165{ }^{\circ} \mathrm{C}$ dan waktu hidrolisis 2 jam yaitu sebesar $31,022 \%$. Selain itu, kadar lignin dan selulosa berfluktuasi seiring meningkatnya suhu hidrolisis. Hal ini disebabkan oleh komposisi bahan baku yang tidak sama pada masing-masing perlakuan.
\end{abstract}

Kata Kunci : bioetanol, ampas tebu, vinasse, hidrolisis termal, recycle vinasse

\begin{abstract}
The purpose of this research are to study the effect of sugarcane bagasse powder concentration, hydrolysis temperature and time on the yield of glucose and the level of glucose by recycle vinasse process. Raw sugarcane bagasse as primary material was obtained from sugarcane juice shop. Observed variabels were concentration of sugarcane bagasse, hydrolysis time and temperature. Sugarcane bagasse is powdered by blender and then mixed with aquadest $(2,94$; $3,85 ; 4,76 \%)$ and hydrolized in the hydrolysis tank. The hydrolysis process occured at 1, 1,5 and 2 hours and temperature 135,150 and $165^{\circ} \mathrm{C}$. The hydrolysis products were tested for its glucose, lignin and cellulose composition. After that, the product was fermented in order to produce bioethanol. The fermented product was filtered for its vinasse and it will be used as the feed of hydrolysis recycle process. Result showed that yield of glucose increases as the increase of sugarcane bagasse powder concentration, hydrolysis time and temperature. But, yield of glucose increases from 1 until 1,5 hour of hydrolysis time and then decreases from 1,5 to 2 hour of hydrolysis time. The highest yield of glucose $(31,022 \%)$ was obtained at concentration $2,94 \%$, $165{ }^{\circ} \mathrm{C}$ and 2 hours of hydrolysis time. Lignin and cellulose level fluctuated as the increasing of hydrolysis temperature. This might be caused by the non-uniform composition by the raw materials.
\end{abstract}

Keywords : bioethanol, sugarcane bagasse, vinasse, thermal hydrolysis, recycle vinasse

\section{Pendahuluan}

Kebutuhan energi nasional ditopang minyak bumi sekitar $51,66 \%$, gas alam $28,57 \%$ dan batubara $15,34 \%$. Persediaan bahan bakar tersebut kian waktu semakin berkurang. Cadangan minyak bumi akan habis sekitar 12 tahun lagi, gas 30 tahun dan batu bara masih bisa dimanfaatkan hingga 70 tahun ke depan. Ketergantungan terhadap bahan bakar fosil ini menjadi masalah besar dan perlu solusi yang mendesak. Salah satu langkah solusinya adalah memanfatkan bioetanol lignoselulosa sebagai alternatif pengganti [15]. 
Produksi etanol dari biomassa adalah salah satu cara untuk mengurangi baik konsumsi minyak mentah dan pencemaran lingkungan [17]. Setiap hektar lahan tebu dapat menghasilkan $10-15$ ton tetes tebu per hektar atau 766 - 1150 liter etanol grade bahan bakar. Luas tanaman tebu Indonesia tahun 2013 adalah 470.000 ha atau potensi maksimum mencapai 3,6 juta kl etanol [4]. Dalam proses produksi di pabrik gula, ampas tebu (bagasse) dihasilkan sebesar $35-40 \%$ dari setiap tebu yang diproses, gula yang termanfaatkan hanya $5 \%$, sisanya berupa tetes tebu (molase), blotong dan air. Selama ini, produk utama yang dihasilkan dari tebu adalah gula, sementara buangan atau hasil samping yang lain tidak begitu diperhatikan [7]. Tulisan ini memaparkan hasil yield glukosa yang dipengaruhi oleh konsentrasi bahan baku, suhu dan waktu hidrolisis, kadar lignin dan selulosa hidrolisat serta yield glukosa hasil hidrolisis recycle vinasse.

\section{Teori}

Bioetanol pada dasarnya merupakan etanol yang diproduksi dari biomassa [14]. Bioetanol dapat dengan mudah diproduksi dari bahan bergula, berpati dan berserat. Tumbuhan yang potensial untuk menghasilkan bioetanol adalah tanaman yang memiliki kadar gula dan karbohidrat tinggi, seperti: tebu, nira, sorgum, ubi kayu, garut, ubi jalar, sagu, jagung, pisang, jerami, bonggol jagung, dan kayu [23].

Etanol yang diproduksi dari bahan berlignoselulosa meliputi dua tahap reaksi. Tahap pertama adalah konversi selulosa menjadi gula. Tahap kedua adalah produksi etanol dari gula hasil konversi. Konversi selulosa menjadi gula dilakukan melalui reaksi hidrolisis [5].

Bagasse merupakan residu padat pada proses pengolahan tebu menjadi gula, yang sejauh ini masih belum banyak dimanfaatkan menjadi produk yang mempunyai nilai tambah (added value). Bagasse yang tergolong biomassa sangat berpeluang untuk dimanfaatkan menjadi sumber energi, makanan ternak atau produk yang berbasis lignoselulosa seperti kertas, biogas, bioetanol dan lain-lain [16].

Bahan lignoselulosa merupakan substrat yang kompleks karena terdiri dari campuran polimer karbohidrat (cellulose dan hemicellulose), lignin dan senyawa-senyawa yang larut dalam air (abu). Dari komponen yang terpenting untuk dikonversi menjadi produk yang berbasis lignoselulosa adalah polisakaridanya. Namun faktanya lignin dengan struktur yang sangat kuat menjadi penghambat dalam konversi polisakaridanya menjadi produk lain. Oleh karena itu banyak riset dibidang biomass yang terus mengembangkan upaya untuk mendegradasi lignin tersebut [16].

Salah satu tahapan pembuatan bioetanol adalah proses fermentasi yang melibatkan Saccharomyces cerevisiae untuk mengubah glukosa menjadi etanol. Saccharomyces cerevisiae tumbuh sangat baik pada suhu 20$30{ }^{\circ} \mathrm{C}$ dan $\mathrm{pH}$ antara 4,5 dan 5,5. Mengenai kebutuhan oksigen, Saccharomyces cerevisiae merupakan mikroorganisme anaerob fakultatif dan umumnya tidak dapat tumbuh dengan baik di bawah kondisi benar-benar anaerobik. Hal ini karena oksigen diperlukan sebagai faktor pertumbuhan untuk membran biosintesis, khusus untuk biosintesis asam lemak (misalnya, asam oleat) dan sterol misalnya, ergosterol [10].

Produk samping proses fermentasi hidrolisat ampas tebu menghasilkan bioetanol terdiri dari 2 jenis, yaitu produk samping berupa padatan dan cairan. Produk samping yang berupa cairan dihasilkan dari proses distilasi menggunakan rotary vacuum pump sedangkan produk samping padatan dari proses pemisahan ampas dengan cairan disebut vinasse.

Secara umum proses pembuatan bioetanol terdiri dari 3 tahap, yaitu : tahap persiapan bahan baku (Pre-treatment), fermentasi dan pemurnian. Perlakuan pendahulan pada lignoselulosa dapat dilakukan secara fisikawi, kimiawi dan biologis [12]. Perlakuan pretreatment (delignifikasi) secara fisika antara lain berupa pencacahan secara mekanik, penggilingan dan penepungan untuk memperkecil ukuran bahan dan mengurangi kristalinitas bahan [8]. Proses pretreatment dilakukan untuk mengkondisikan bahan-bahan lignoselulosa baik dari segi struktur dan ukuran dengan memecah dan menghilangkan kandungan lignin dan hemiselulosa, merusak struktur kristal dari selulosa serta meningkatkan porositas bahan [22]. Rusaknya struktur kristal selulosa akan mempermudah terurainya selulosa menjadi glukosa. Selain itu, hemiselulosa akan turut terurai menjadi senyawa gula sederhana (glukosa, galaktosa, manosa, heksosa, pentosa, xilosa dan arabinosa) [18]. Proses pretreatment lanjutan dilakukan dengan hidrolisis termal. Dimana pada hidrolisis termal digunakan tekanan dan temperatur yang tinggi, untuk memisahkan komponen organiknya, menghidrolisis hemiselulosa dan mengubah sifat-sifat 
selulosa dan lignin [9]. Pada hidrolisis termal digunakan medium pemanas berupa air. Dengan penggunaan medium air tadi maka korosi terhadap perangkat hidrolisis lebih dapat diminimalisasi dibandingkan dengan penggunaan asam. Jenis hidrolisis ini juga hanya sedikit menghasilkan produk samping yang tidak diinginkan serta limbah yang dihasilkan bersifat ramah lingkungan. Keunggulan dari hidrolisis termal dibandingkan dengan jenis hidrolisis lain adalah proses hidrolisis dengan perlakuan panas tidak memerlukan tahap lebih lanjut seperti tahap pemurnian, tidak perlu dilakukan penyesuaian $\mathrm{pH}$, maupun penggunaan katalis [19].

Tahapan selanjutnya adalah proses fermentasi yang berlangsung beberapa jam setelah semua bahan dimasukkan ke dalam fermentor. Proses ini berjalan ditandai dengan keluarnya gelembung-gelembung udara kecilkecil Gelembung-gelembung udara ini adalah gas $\mathrm{CO}_{2}$ yang dihasilkan selama proses fermentasi. Selama proses fermentasi diusahakan agar suhu tidak melebihi $36^{\circ} \mathrm{C}$ dan $\mathrm{pH}$ nya dipertahankan $4.5-5$. Proses fermentasi berjalan kurang lebih selama 2 sampai 3 hari [20].

Tahapan terakhir dalam pembuatan bioetanol ini adalah proses pemurnian etanol, dimana proses yang paling banyak digunakan dalam dunia industri adalah proses distilasi. Kadar etanol yang terhitung dari hasil distilasi sebenarnya lebih kecil dibandingkan kadar etanol yang sebenarnya terkandung dalam cairan fermentasi. Hal ini disebabkan karena pengukuran kadar etanol dilakukan dengan menggunakan metode distilasi [13]. Menurut Amerine dan Ough [1], distilasi etanol akan menyebabkan kehilangan etanol sebanyak 0,6$1,5 \%(\mathrm{v} / \mathrm{v})$.

\section{Metodologi Penelitian}

\section{Bahan dan Peralatan Penelitian}

Bahan yang digunakan adalah tepung ampas tebu dan akuades. Peralatan utama yang digunakan adalah tangki hidrolisis dan blender.

\section{Persiapan Bahan Baku (Pretreatment)}

Ampas tebu disortasi, dipilih yang bagus kemudian dikeringkan dibawah sinar matahari. Setelah kering, ampas tebu tersebut dihancurkan dengan menggunakan blender menjadi berbentuk powder. Tepung ampas tebu lalu disimpan dalam wadah plastik yang kedap udara agar bahan baku tidak terkontaminasi.

\section{Proses Hidrolisis Termal}

Sampel ampas tebu yang sudah melewati tahap pretreatment dicampur dengan akuades dengan konsentrasi tepung ampas tebu masing-masing sebesar 2,94, 3,85 dan 4,76\% massa total 4000 gram. Kemudian dihidrolisis dengan menggunakan tangki hidrolisis yang sudah didesain khusus masing-masing pada suhu 135,150 dan $165^{\circ} \mathrm{C}$ selama $1,1,5$ dan 2 jam hingga menjadi berbentuk slurry. Setelah proses hidrolisis selesai, tangki diangkat dan didinginkan mendadak untuk menghentikan proses hidrolisis. Pendinginan mendadak dilakukan dengan cara memasukkan tangki ke dalam ember yang berisi air keran hingga suhunya menjadi sama dengan suhu ruangan.

\section{Proses Fermentasi}

Hasil hidrolisis dimasukkan ke dalam tempat fermentasi dan ditambahkan ragi sebanyak $5 \%$ dari massa substrat dan urea sebanyak $0,05 \%$ dari massa yang akan difermentasi. Fermentasi dilakukan pada suhu ruangan selama 12 jam dalam keadaan anaerob.

\section{Proses Distilasi}

Hasil fermentasi lalu dimurnikan melalui proses distilasi pada suhu $75^{\circ} \mathrm{C}$ dengan menggunakan rotary vacuum pump. Sisa hasil distilasi disaring dan diambil padatannya (vinasse). Sedangkan distilat ditampung lalu diukur volume distilat, dan kadar bioetanol yang diperoleh.

\section{Proses Recycle Vinasse}

Vinasse (produk samping fermentasi) dijadikan bahan baku untuk umpan hidrolisis pada suhu $150{ }^{\circ} \mathrm{C}$ selama 1,5 jam.

\section{Prosedur Analisa}

Hasil hidrolisis dianalisa kadar glukosa dengan metode luff Schorrl [3] serta kadar lignin dan selulosa dengan metode Chesson [21].

\section{Hasil dan Pembahasan}

Pengaruh Konsentrasi Tepung Ampas Tebu terhadap Yield Glukosa

Gambar 1 memperlihatkan pengaruh konsentrasi bahan baku terhadap yield glukosa pada waktu hidrolisis 1, 1,5 dan 2 jam pada pembuatan bioetanol dari tepung ampas tebu. 


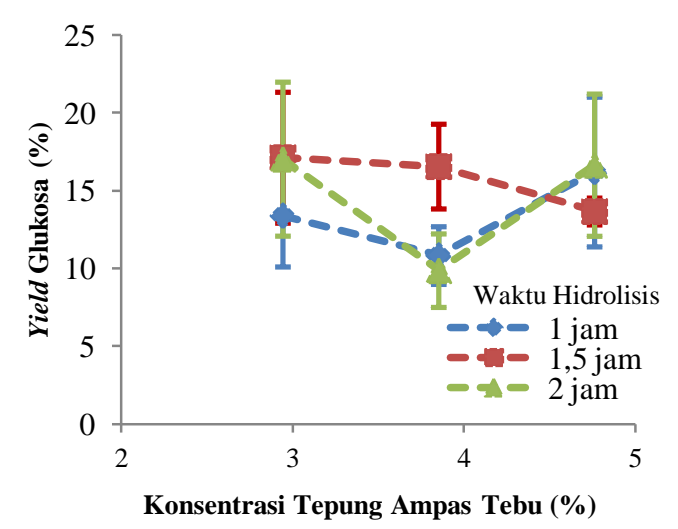

Gambar 1. Pengaruh Konsentrasi Tepung Ampas Tebu terhadap Yield Glukosa

Pada gambar 1 terlihat bahwa yield glukosa yang diperoleh pada suhu hidrolisis 135,150 dan $165^{\circ} \mathrm{C}$ dengan waktu hidrolisis 1, 1,5 dan 2 jam secara umum berfluktuasi. Perolehan yield glukosa cenderung turun pada konsentrasi tepung ampas tebu 3,85\% dan kemudian meningkat pada konsentrasi $4,76 \%$. Penurunan yield glukosa juga terlihat pada konsentrasi tepung ampas tebu 4,76\% waktu hidrolisis 1,5 jam. Fluktuasi dan penurunan yield glukosa ini juga terlihat pada hasil penelitian oleh Mandagi, dkk. [19] yang meneliti tentang hidrolisis termal dengan bahan baku eceng gondok serta Sutjiadi, dkk. [11] yang meneliti tentang hidrolisis termal dengan bahan baku kertas bekas. Hal ini dapat disebabkan oleh ketidakstabilan kondisi operasi dimana suhu tangki hidrolisis yang selalu berubah sehingga sulit dicapai suhu konstan yang diinginkan setiap menitnya.

\section{Pengaruh Suhu Hidrolisis Terhadap Yield Glukosa}

Gambar 2 memperlihatkan pengaruh suhu hidrolisis terhadap yield glukosa pada pembuatan bioetanol dari tepung ampas tebu.

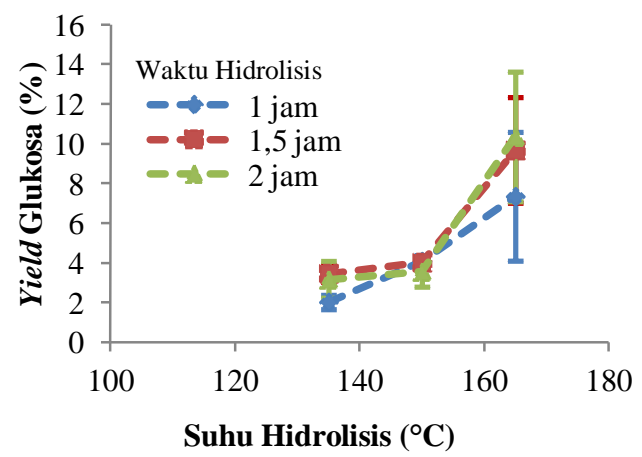

Gambar 2. Pengaruh Suhu Hidrolisis terhadap Yield Glukosa
Pada gambar 2 terlihat bahwa yield glukosa yang diperoleh pada konsentrasi tepung ampas tebu 2,$94 ; 3,85$ dan $4,76 \%$ dengan waktu hidrolisis 1, 1,5 dan 2 jam semakin meningkat seiring dengan meningkatnya suhu hidrolisis. Hasil ini sesuai dengan penelitian Sutjiadi, dkk. [11], Mandagi, dkk. [19] dan Pratiwi, dkk. [6]. Hal ini disebabkan oleh semakin banyaknya monomer-monomer gula yang terlepas dari ikatannya seiring meningkatnya suhu maka perolehan yield glukosa pun semakin tinggi.

\section{Pengujian Kadar Glukosa, Lignin Dan Selulosa Dengan Variasi Suhu Hidrolisis}

Struktur dasar dari biomassa lignoselulosa terdiri dari 3 polimer utama yaitu selulosa $\left(\mathrm{C}_{6} \mathrm{H}_{10} \mathrm{O}_{5}\right)_{\mathrm{x}}$, hemiselulosa seperti xylan $\left(\mathrm{C}_{5} \mathrm{H}_{8} \mathrm{O}_{4}\right)_{\mathrm{m}}$ dan lignin $\left[\mathrm{C}_{6} \mathrm{H}_{10} \mathrm{O}_{5} \cdot\left(\mathrm{OCH}_{3}\right)_{0,9-1,7}\right]_{\mathrm{n}}$ (17). Tabel 1 menunjukkan hasil pengujian yield glukosa, lignin dan selulosa pada konsentrasi bahan baku 2,94\% dan waktu hidrolisis 1 jam serta tabel 2 menunjukkan hasil pengujian kadar glukosa, lignin dan selulosa bahan baku (tanpa hidrolisis) dan vinasse.

Tabel 1. Kadar Glukosa, Lignin dan Selulosa dengan Variasi Suhu Hidrolisis

\begin{tabular}{|c|c|c|c|}
\hline $\begin{array}{c}\text { Tempe- } \\
\text { ratur } \\
\left({ }^{\circ} \mathbf{C}\right)\end{array}$ & $\begin{array}{c}\text { Kadar } \\
\text { Lignin } \\
(\mathbf{\%})\end{array}$ & $\begin{array}{c}\text { Kadar } \\
\text { Selulosa } \\
(\boldsymbol{\%})\end{array}$ & $\begin{array}{c}\text { Kadar } \\
\text { Glukosa } \\
(\boldsymbol{\%})\end{array}$ \\
\hline 135 & 12,57 & 52,75 & 1,48 \\
\hline 150 & 11,97 & 52,80 & 1,72 \\
\hline 165 & 21,09 & 50,18 & 4,14 \\
\hline
\end{tabular}

Tabel 2. Kadar Glukosa, Lignin dan Selulosa dari Bahan Baku (Tanpa Hidrolisis) dan Vinasse

\begin{tabular}{|c|c|c|c|}
\hline Sampel & $\begin{array}{c}\text { Kadar } \\
\text { Lignin } \\
(\boldsymbol{\%})\end{array}$ & $\begin{array}{c}\text { Kadar } \\
\text { Selulosa } \\
(\%)\end{array}$ & $\begin{array}{c}\text { Kadar } \\
\text { Glukosa } \\
(\%)\end{array}$ \\
\hline $\begin{array}{c}\text { Tanpa } \\
\text { Hidrolisis }\end{array}$ & 9,24 & 43,83 & - \\
\hline Vinasse & 24,78 & 52,98 & 1,94 \\
\hline
\end{tabular}

Pada tabel 1 dan 2 terlihat bahwa kadar lignin, selulosa dan glukosa berfluktuasi seiring dengan meningkatnya temperatur hidrolisis. Menurut Garrote, et al., proses hidrolisis termal pada tekanan dan temperatur tinggi akan menghidrolisis hemiselulosa serta mengubah sifat selulosa dan lignin, namun hasil yang diperoleh berbeda. Hal ini disebabkan oleh komposisi dari bahan baku yang tidak seragam. 


\section{Pengujian Kadar Glukosa Dengan Recycle Vinasse}

Tabel 3 menunjukkan hasil pengujian kadar glukosa hasil hidrolisis termal dengan suhu $150{ }^{\circ} \mathrm{C}$ dan waktu 1,5 jam.

Tabel 3. Kadar Glukosa Hasil Hidrolisis Bahan Baku dan Recycle Vinasse

\begin{tabular}{|c|c|}
\hline Sampel & $\begin{array}{c}\text { Kadar } \\
\text { Glukosa } \\
(\boldsymbol{\%})\end{array}$ \\
\hline Hasil Hidrolisis 2,94\% & 1,72 \\
\hline Vinasse & 1,94 \\
\hline $\begin{array}{c}\text { Hasil Hidrolisis Recycle } \\
\text { Vinasse }\end{array}$ & 1,06 \\
\hline
\end{tabular}

Pada tabel 3 dapat dilihat bahwa kadar glukosa hasil recycle vinasse masih cukup tinggi yaitu sebesar $61,63 \%$ dari kadar glukosa hasil hidrolisis bahan baku. Penelitian Rusdianto [2] menyatakan hasil yang serupa bahwa vinasse mempunyai potensi untuk digunakan kembali sebagai bahan baku pebuatan etanol karena sisa kandungan glukosa sebesar $15,62 \%$ dari kandungan glukosa awal untuk bahan baku ubi kayu.

\section{Pengaruh Suhu Hidrolisis Terhadap Kadar Bioetanol}

Gambar 3 berikut memperlihatkan pengaruh suhu hidrolisis terhadap perolehan kadar bioetanol pada pembuatan bioetanol dari tepung ampas tebu.

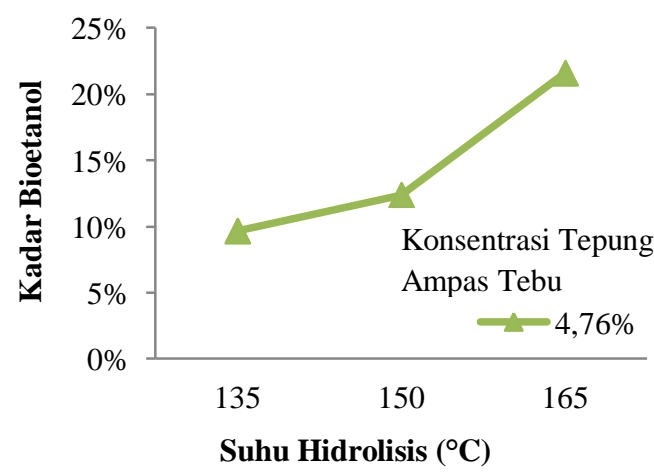

Gambar 3. Pengaruh Suhu Hidrolisis terhadap Kadar Bioetanol pada Waktu Hidrolisis 2 jam

Pada gambar 3 terlihat bahwa kadar bioetanol yang diperoleh pada konsentrasi tepung ampas tebu $4,76 \%$ dengan waktu hidrolisis 2 jam semakin meningkat seiring dengan meningkatnya suhu hidrolisis. Hal ini sesuai dengan pembahasan mengenai kadar glukosa yang telah dipaparkan pada bagian sebelumnya mengenai kadar glukosa bahwa kadar glukosa meningkat seiring dengan meningkatnya suhu hidrolisis. Menurut pernyataan Walker [10], Saccharomyces cerevisiae merupakan mikroba bioetanol dominan yang mampu memfermentasi gula utama (misalnya glukosa, fruktosa, sukrosa, maltosa) sehingga perolehan kadar bioetanol turut meningkat seiring dengan meningkatnya yield glukosa

\section{Kesimpulan}

Adapun kesimpulan yang dapat diambil dari penelitian ini adalah:

1. Perolehan yield glukosa yang diperoleh secara umum berfluktuasi namun pada beberapa titik kadar glukosa yang diperoleh meningkat seiring dengan meningkatnya konsentrasi tepung ampas tebu (kepekatan bahan baku) dari 2,94 sampai $4,76 \%$. Pada penelitian ini yield glukosa tertinggi yang diperoleh pada konsentrasi tepung ampas tebu adalah $4,76 \%$.

2. Perolehan yield glukosa dan kadar bioetanol meningkat seiring dengan meningkatnya suhu hidrolisis dari $135{ }^{\circ} \mathrm{C}$ sampai $165^{\circ} \mathrm{C}$ dimana pada penelitian ini yield glukosa dan kadar bioetanol tertinggi diperoleh pada suhu hidrolisis $165{ }^{\circ} \mathrm{C}$ dengan waktu hidrolisis 2 jam.

3. Vinasse dapat di-recycle dan dapat dimanfaatkan kembali menjadi bahan baku hidrolisis karena masih memiliki kandungan glukosa $(1,94 \%)$ yang tidak berbeda jauh dengan kandungan glukosa pada bahan baku awal.

\section{Daftar Pustaka}

[1] Amerine dan Ough, Methode of Analysis of Must and Wines, A WileyInterscience Publication, New York, 1979.

[2] Andrew Setiawan Rusdianto, Kajian Proses Produksi Bioetanol Dari Ubi Kayu Dengan Daur Ulang Vinasse Sebagai Umpan Balik Proses Fermentasi, Tesis, Pasca sarjana IPB, Bogor, 2010.

[3] Badan Standar Nasional, Cara Uji Gula, SNI 01-2892, Jakarta, 1992.

[4] BPPT, Outlook Energi Indonesia 2014, Jakarta, 2014, p. 98-99.

[5] Broto, S. Kardono, Teknologi Pembuatan Etanol Berbasis Lignoselulosa Tumbuhan Tropis untuk Produksi Biogasoline. Laporan Akhir, Program Insentif Peneliti dan Perekayasa LIPI, Serpong, 2010. 
[6] Dyah Pratiwi M., Dahlia Qadari, Nurul Utami SM, Potensi Pembuatan Etanol dari Eceng Gondok Melalui Proses Hidrothermal, Tugas Akhir, Politeknik Negeri Ujung Pandang, Makassar, 2013.

[7] Erni Misran, Industri Tebu Menuju Zero Waste Industry, Jurnal Teknologi Proses, ISSN 1412-7814, 4(2) : 6-10, 2005.

[8] Euis Hermiati, dkk., Pemanfaatan Biomassa Lignoselulosa Ampas Tebu untuk Produksi Bioetanol, Jurnal Litbang Pertanian, 29 (4) : hal. 121-130, 2010.

[9] G. Garrote, H. Dominguez, J.C. Parajo, Hydrothermal Processing of Lignucellulosic Materials, Holz als Roh -und Werksoff, 57 : 191- 202, 1999.

[10] Graeme M. Walker, Bioethanol : Science and Technology of Fuel Alcohol, Systool Software, Scotlandia, 2010.

[11] Henry Andrian Sutjiadi, Henry Hardosubroto, Buana Girisuta, Optimisasi Proses Hidrolisis Kertas Hidrolisis Kertas Bekas dengan Menggunakan Metode Hidrolisis Termal, Prosiding Seminar Nasional Teknik Kimia "Kejuangan"Universitas Katolik Parahyangan, Bandung, ISSN 1693-4393, 2010.

[12] Ida Bagus Wayan Gunam, dkk., Delignifikasi Ampas Tebu dengan Larutan Natrium Hidroksida Sebelum Proses Sakarifikasi Secara Enzimatis Menggunakan Enzim Selulase Kasar dari Aspergillus niger FNU 6018, Jurnal Teknologi, 34 (2011), p. 24-32.

[13] Isra Dharma Suyandra, Pemanfaatan Hidrolisat Pati Sagu (Metroxylon sp.) sebagai Sumber Karbon Pada Fermentasi Etanol oleh Saccharomyces cerevisisae, Skripsi, Fakultas Teknologi Pertanian, Institut Pertanian Bogor, Bogor, 2007.

[14] J.D. McMillan, Enzymatic Conversion of Biomass for Fuels Production, American Chemical Society, Washington DC, 1994 p. 292-324.

[15] Kementrian Riset dan Teknologi Pemanfaatan Bioetanol Untuk Kebutuhan Energi Indonesia, RISTEK, http://www.ristek.go.id, diakses pada 02 Mei 2012.

[16] Muhammad Samsuri, Bambang Prasetya dan Misri Gozan, Lignin Biodegradasi pada Bagasse oleh Jamur Pelapuk Putih (White Rot Fungi) dan Potensi Pemanfaatannya menjadi Senyawa Berbasis Lignoselulosa, Laporan
Perancangan Produk Jurusan Teknik Kimia, Fakultas Teknik UI, Depok, 2005.

[17] Mustafa Balat, Havva Balat, Cahide Oz, Progress in Bioethanol Processing, 34: 551-573, 2008.

[18] N. Mosier, et al.,. Hendrickson. Features of Promising Technologies for Pretreatment of Lignocellulosic Biomass, Bioresource Technology, 96: 6673-686, 2005.

[19] Reza Mandagi, Yoke Anugerah dan Buana Girisuta, Optimasi Proses Perlakuan Awal dalam Menyingkap Fraksi Hemiselulosa Eceng Gondok Menggunakan Metode Hidrolisis Termal, Prosiding Seminar Nasional Teknik Kimia "Kejuangan" Universitas Katolik Parahyangan, Bandung, ISSN 1693-4393, 2010.

[20] Sri Komarayati, Gusmailina. Prospek Bioetanol Sebagai Pengganti Minyak Tanah. Pusat Penelitian dan Pengembangan Hasil Hutan, Bogor. Review, 2010.

[21] Widya, Pertumbuhan, Kandungan Selulosa dan Lignin pada Rami (Boehmeria nivea L. Gaudich) dengan Pemberian Asam Giberelat $\left(\mathrm{GA}_{3}\right)$, Jurnal, ISSN : 1412-033, 9(4) : hal. 269-274, 2008.

[22] Ye Sun, Jiayang Cheng, Hydrolysis of lignocellulosic materials for ethanol production: a review, Bioresource Technology, 83 : 1-11, 2002.

[23] Yurida Tri Wijayanti. Pembuatan Bioetanol dari Buah Salak dengan Proses Fermentasi dan Distilasi, Tugas Akhir, Program Diploma, Universitas Diponegoro, Semarang, 2011. 